\title{
Erratum
}

\section{Revista da Sociedade Brasileira de Medicina Tropical} Journal of the Brazilian Society of Tropical Medicine

Burden of disease attributable to Risk Factors in Brazil: an analysis of national and subnational estimates from the 2019 Global Burden of Disease study

Vol.:55(suppl 1): 2022 - doi: https://doi.org/10.1590/0037-8682-0262-2021 - FIGURE 2B - Page 6/10

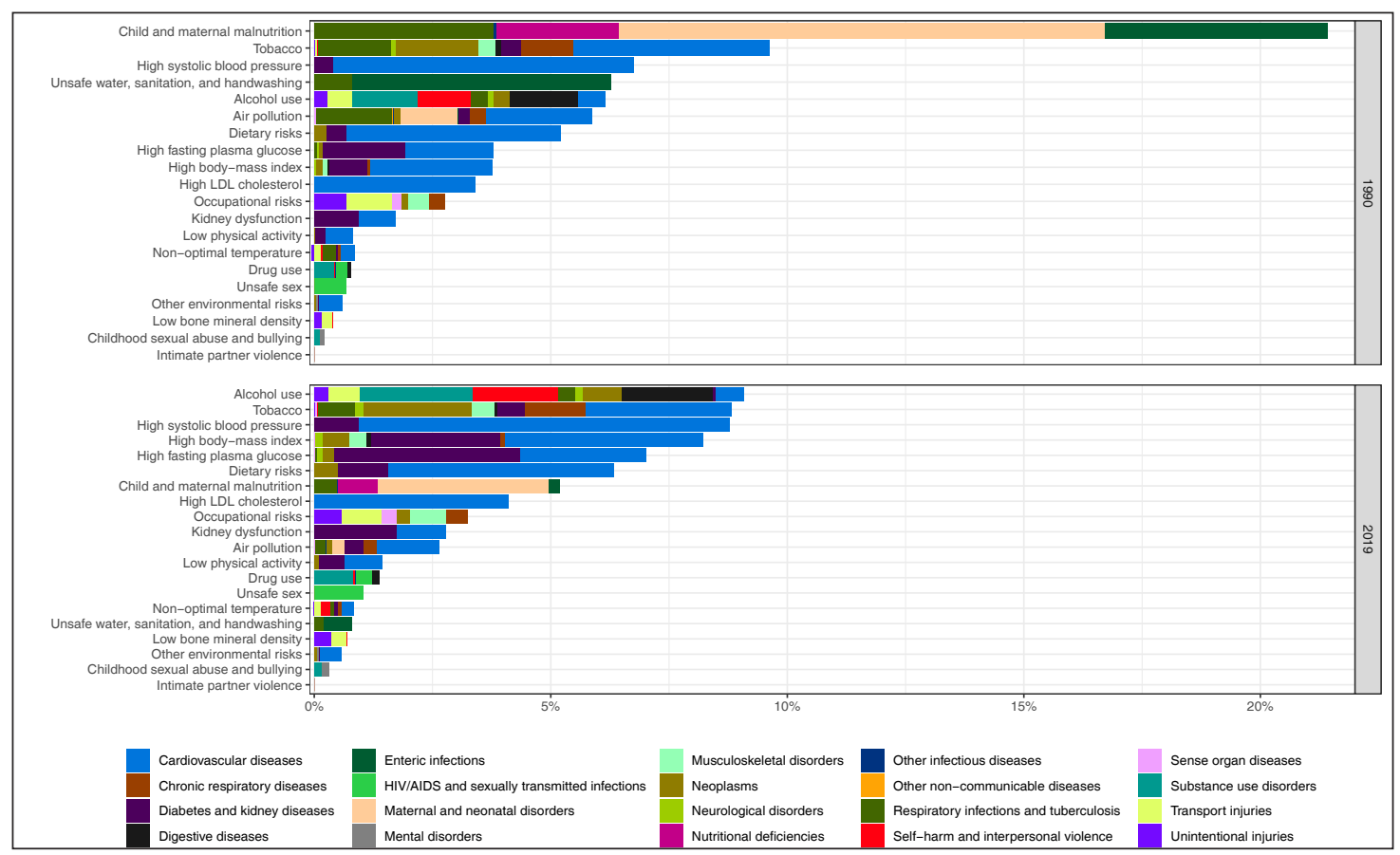

Should read:

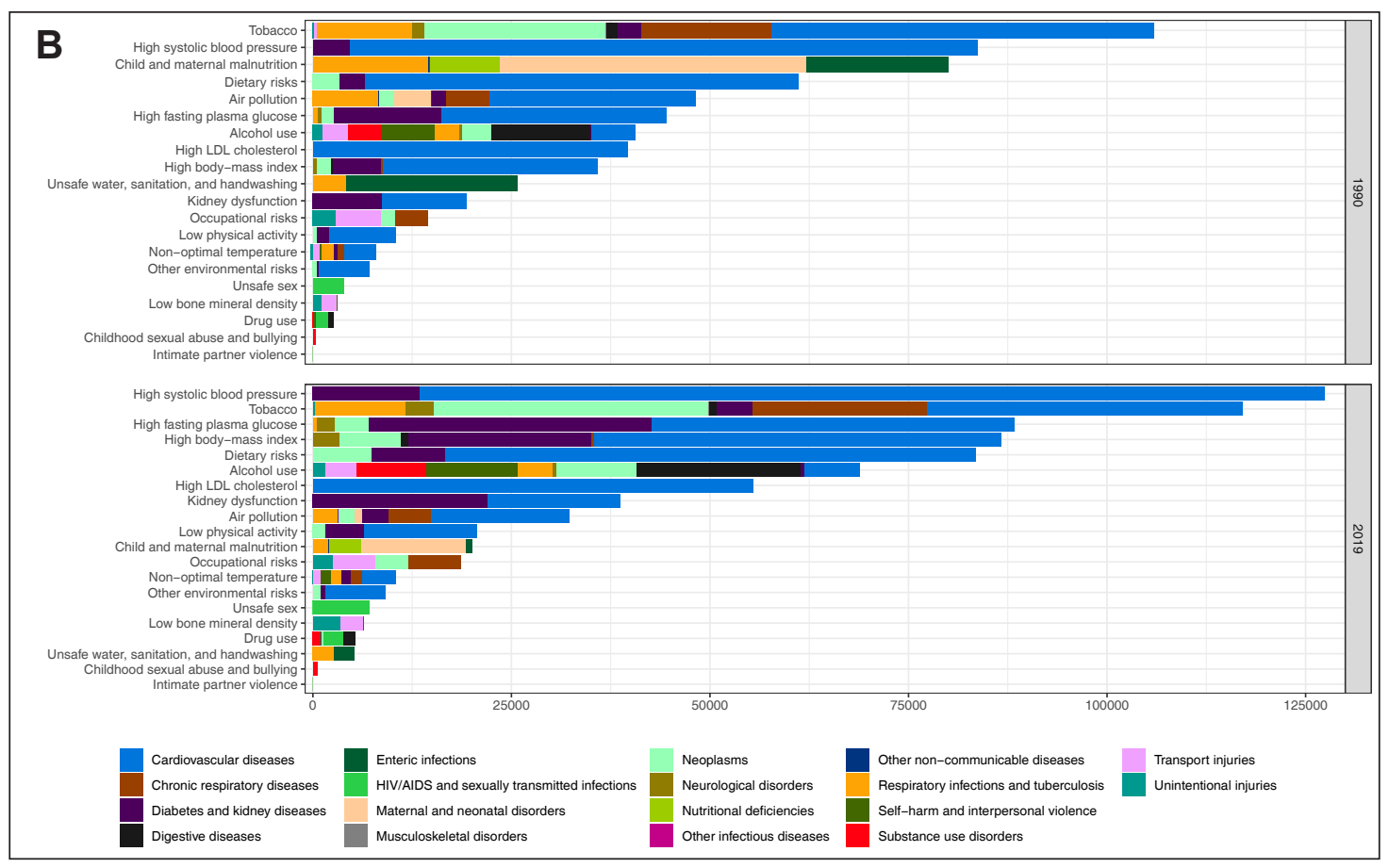

